\title{
Peroxyoxalate chemiluminescence enhanced by oligophenylenevinylene fluorophores in the presence of various surfactants
}

Jiro Motoyoshiya* and Setsuko Takigawa

\begin{abstract}
The effect of several surfactants on peroxyoxalate chemiluminescence (PO-CL) using oligophenylenevinylene fluorophores was investigated. Among several oligophenylenevinylenes consisting of some stilbene units, linearly conjugated ones, such as distyrylbenzene and distyrylstilbene, effectively enhanced PO-CL efficiency. Various effects of anionic, cationic, amphoteric and non-ionic surfactants on the CL efficiency of PO-CL were determined using three oxalates and the distyrylbenzene fluorophore. Anionic and non-ionic surfactants effectively enhanced CL efficiency, in contrast to the negative effect of cationic and amphoteric surfactants. Non-ionic surfactants were also effective in CL reactions of oxalates bearing dodecyl ester groups by the hydrophobic interaction between their alkyl chains. Considering these results, the surfactants not only increase the concentrations of water-insoluble interacting species in the hydrophobic micelle cores, but also control rapid degradation of the oxalates by alkaline hydrolysis.
\end{abstract}

Keywords: peroxyoxalate chemiluminescence; oligophenylenevinylene; distyrylbenzene; surfactant

* Correspondence to: J. Motoyoshiya, Course of Applied Chemistry, Division of Chemistry and Materials, Faculty of Textile Science and Technology, Shinshu University, Ueda, Nagano 386-8567, Japan. E-mail: jmotoyo@shinshu-u.ac.jp

Course of Applied Chemistry, Division of Chemistry and Materials, Faculty of Textile Science and Technology, Shinshu University, Ueda, Nagano 386-8567, Japan

\section{Introduction}

Peroxyoxalate chemiluminescence (PO-CL), the most effective of the various chemiluminescence (CL) systems (1), has received much attention since its discovery (2). PO-CL can be readily carried out by the reaction of active oxalates, such as bis(2,4,6-trichlorophenyl) oxalate (TCPO) or bis(2,4-dinitrophenyl) oxalate (DNPO), as luminophores and hydrogen peroxide in the presence of various types of fluorophores. Because of its practical simplicity and high efficiency, PO-CL is not 
only used as a chemical light source, but is also comprehensively applied to analytical chemistry. A wide variety of chemical and biological analytes can be both qualitatively and quantitatively determined using these CL systems as signals of light emission $(3,4)$. However, there are some problems with this CL system, namely, both oxalates and fluorophores are generally insoluble in aqueous media and active oxalates are unstable in aqueous conditions; PO-CL reactions are generally performed in aqueous media due to the use of aqueous hydrogen peroxide as an oxidizing agent. In addition, hydrophobic environments are favorable for the chemiexcitation step in which the hydrophobic fluorophores and high-energy intermediates such as 4-aryloxy-4-hydroxy-1,2dioxetane-3-ones or 1,2-dioxetane-3,4-dione interact. An effort to improve these deficiencies has been made using some water-soluble oxamides (5), but they have not been used in practice. Another simple method is the use of surfactants, which lead to changes in the microenvironments in which reactive intermediates take part in the chemiexcitation steps by interacting with the fluorophores. Several reports have dealt with the effects of surfactants on PO-CL, and various effects of neutral, cationic and anionic surfactants on the CL efficiency have been documented (6-14), however, these results cannot be easily integrated into a simple system because surfactants behave in different ways depending on the reactants and the reaction conditions.

By contrast, many aromatic fluorophores have been used for PO-CL, and we have shown that 1,4-distyrylbenzenes are very useful in PO-CL systems because of their strong fluorescence, controllable emission wavelength and synthetic availability (15-17). Because distyrylbenzene is one of the oligophenylenevinylenes useful as a fluorescent material for optoelectronic and photonic devices $(18,19)$, it is interesting to use some low molecular mass oligophenylenevinylenes as fluorophores for PO-CL systems.

Here, we report the preparation and physical properties of some fluorescent oligophenylenevinylenes consisting of some stilbene units, and their use in a PO-CL system with three oxalates. In addition, the effects of various anionic, cationic, amphoteric and non-ionic surfactants on the CL efficiency are reported.

\section{Experimental}

\section{Apparatus}

${ }^{1} \mathrm{H}-,{ }^{13} \mathrm{C}$-, and ${ }^{31} \mathrm{P}-\mathrm{NMR}$ spectra were measured on a Bruker AVANCE-400 at $400 \mathrm{MHz}$ for ${ }^{1} \mathrm{H}-\mathrm{NMR}, 100 \mathrm{MHz}$ for ${ }^{13} \mathrm{C}-\mathrm{NMR}$, and $125 \mathrm{MHz}$ for ${ }^{31} \mathrm{P}-\mathrm{NMR}$, respectively, in $\mathrm{CDCl}_{3}$. The chemical shifts $(\delta)$ are reported in ppm downfield from TMS as an internal standard or from the residual solvent peak for ${ }^{1} \mathrm{H}$ - and ${ }^{13} \mathrm{C}-\mathrm{NMR}$. Coupling constants $(J)$ are reported in Hz. Low 
resolution mass spectra (MS) were recorded by the JEOL JMS-K9 spectrometers. Elemental analysis was recorded on a Perkin-Elmer 2400CHN elemental analyzer. Column chromatography was performed on silica gel (E. Merck). Absorption and fluorescence spectra were recorded on a U-3310 spectrometer (Hitachi) and on a RF-5000 spectrometer (Shimadzu), respectively. Fluorescence quantum yields $\left(\Phi_{\mathrm{F}}\right)$ were estimated using 9,10 -diphenylanthracene $\left(\Phi_{\mathrm{F}}=0.91\right.$ in benzene) as a standard. The measurements of the total chemiluminescence quantum yield $\left(\Phi_{\mathrm{CL}}\right)$ were carried out by a photon-counting method using a Hamamatsu Photonics R464 photomultiplier connected to a photon-counting unit (C3866) and a photon-counting board M8784 according to a previously reported procedure [16], and the luminol chemiluminescence was used as the standard in DMSO for calibration of the photomultiplier tube.

\section{Materials}

All commercially available chemicals and solvents were of the highest purity or purified by the standard method. The known compound, 4,4'-bis[(2'-ethylhexyloxy)styryl]stilbene (3), was prepared according to the reported procedure by us (20).

\section{Synthesis of 4-(2'-ethylhexyloxy)benzylphosphonic acid diethyl ester}

A mixture of triethyl phosphite $(6 \mathrm{~mL}, 34.4 \mathrm{mmol})$ and 4-(2'-ethylhexyloxy)benzyl bromide (10.2 g, $34.3 \mathrm{mmol}$ ), prepared from $p$-hydroxybenzaldehyde by alkylation with 2-ethylhexyl bromide, reduction to the alcohol, and bromination with hydrobromic acid, was heated at $130{ }^{\circ} \mathrm{C}$ overnight. Purification by column chromatography gave the product as a colorless oil (10. $5 \mathrm{~g}, 86 \%)$. ${ }^{1} \mathrm{H}-\mathrm{NMR}$ $\delta$ 0.88-0.94 (m, 6H, OCH$\left.{ }_{2} \mathrm{CH}\left(\mathrm{CH}_{2} \mathrm{CH}_{3}\right)\left(\mathrm{CH}_{2}\right)_{3} \mathrm{CH}_{3}\right), 1.24 \quad\left(\mathrm{t}, 6 \mathrm{H}, J=7.07 \mathrm{~Hz}, \mathrm{P}(\mathrm{O})\left(\mathrm{OCH}_{2} \mathrm{CH}_{3}\right)_{2}\right)$, 1.27-1.53 (m, 8H, $\left.\mathrm{OCH}_{2} \mathrm{CH}\left(\mathrm{CH}_{2} \mathrm{CH}_{3}\right)\left(\mathrm{CH}_{2}\right)_{3} \mathrm{CH}_{3}\right), \quad 1.71$ (septet, $1 \mathrm{H}, \quad J=6.03 \mathrm{~Hz}$, $\left.\mathrm{OCH}_{2} \mathrm{CH}\left(\mathrm{CH}_{2} \mathrm{CH}_{3}\right)\left(\mathrm{CH}_{2}\right)_{3} \mathrm{CH}_{3}\right), 3.82\left(\mathrm{~d}, 2 \mathrm{H}, J=6.03, \mathrm{~Hz}, \mathrm{OCH}_{2} \mathrm{C}_{7} \mathrm{H}_{15}\right), 3.96-4.05(\mathrm{~m}, 4 \mathrm{H}$, $\left.\mathrm{OCH}_{2} \mathrm{P}(\mathrm{O})\left(\mathrm{OCH}_{2} \mathrm{CH}_{3}\right)_{2}\right), 3.08\left(\mathrm{~d}, 2 \mathrm{H}, J_{\mathrm{HP}}=21.0 \mathrm{~Hz}, \mathrm{OCH}_{2} \mathrm{P}(\mathrm{O})\right), 6.84(\mathrm{~d}, 2 \mathrm{H}, J=8.04 \mathrm{~Hz}, \mathrm{Ar}-H)$, $7.19(\mathrm{dd}, 2 \mathrm{H}, J=2.53,8.59 \mathrm{~Hz}, \mathrm{Ar}-H) .{ }^{31} \mathrm{P}$ NMR (85\% phosphoric acid as an external standard), $\delta$ 27.3.

\section{Synthesis of 4'-(2'-ethylhexyloxy)-4-(2'-ethylhexyloxy)stilbene (1)}

To a suspension of tert-BuOK (1.43 g, $12.8 \mathrm{mmol})$ in THF (tetrahydrofuran) (15 mL) was added a solution of the phosphonic acid ester $(2.28 \mathrm{~g}, 6.40 \mathrm{mmol})$ prepared above in THF $(20 \mathrm{~mL})$ and a solution of 4-(2'-ethylhexyloxy)benzaldehyde (1 g, $4.27 \mathrm{mmol})$ in THF (20 mL) in this order under 
a nitrogen atmosphere. After the solution was stirred for $4 \mathrm{~h}$ at an ambient temperature, the solvent was removed under a reduced pressure and the residue was treated with benzene and saturated ammonium chloride solution. The organic layer was washed with brine and dried over anhydrous sodium sulfate. Removal of the solvent and purification by column chromatography on a silica gel using benzene as an eluant gave the product as a white powder $\left(1.25 \mathrm{~g}, 76 \%\right.$ \%. M.p 74-78 ${ }^{\circ} \mathrm{C}$. ${ }^{1} \mathrm{H}-\mathrm{NMR}, \quad \delta \quad 0.88-0.95 \quad\left(\mathrm{~m}, \quad 12 \mathrm{H}, \quad \mathrm{OCH}_{2} \mathrm{CH}\left(\mathrm{CH}_{2} \mathrm{CH}_{3}\right)\left(\mathrm{CH}_{2}\right)_{3} \mathrm{CH}_{3}\right), \quad 1.30-1.49 \quad(\mathrm{~m}, \quad 16 \mathrm{H}$, $\left.\mathrm{OCH}_{2} \mathrm{CH}\left(\mathrm{CH}_{2} \mathrm{CH}_{3}\right)\left(\mathrm{CH}_{2}\right)_{3} \mathrm{CH}_{3}\right), 3.85\left(\mathrm{~d}, 4 \mathrm{H}, J=5.6 \mathrm{~Hz}, \mathrm{OCH}_{2}\right), 6.88$ (d, 4H, $\left.J=8.4 \mathrm{~Hz}, \mathrm{Ar}-\mathrm{H}\right)$, $6.91(\mathrm{~s}, 2 \mathrm{H}, \mathrm{CH}=\mathrm{CH}), 7.40(\mathrm{~d}, 2 \mathrm{H}, J=8.4 \mathrm{~Hz}, \mathrm{Ar}-\mathrm{H}) . \mathrm{MS} \mathrm{m} / \mathrm{z}=436\left(\mathrm{M}^{+}\right)$. Anal. Calcd for $\mathrm{C}_{30} \mathrm{H}_{44} \mathrm{O}_{2}, \mathrm{C}, 82.52 ; \mathrm{H}, 10.16(\%)$. Found, C; 82.67, H; 10.18 (\%).

\section{Synthesis of 1,4-bis[(2'-ethylhexyloxy)styryl]benzene (2)}

To a suspension of tert-BuOK (1.16 g, $7.16 \mathrm{mmol})$ in DMF (dimethyl formamide) (10 $\mathrm{mL})$ was added a solution of the phosphonic acid ester $(2.55 \mathrm{~g}, 7.16 \mathrm{mmol})$ in DMF $(10 \mathrm{~mL})$ and under a solution of terephthalaldehyde $(0.48 \mathrm{~g}, 3.58 \mathrm{mmol})$ in DMF $(19 \mathrm{~mL})$ in this order under a nitrogen atmosphere. After the solution was stirred overnight at an ambient temperature, the solvent was removed and the residue was treated with ethyl acetate, diluted hydrochloric acid, and saturated ammonium chloride solution. The organic layer was washed with brine and dried over anhydrous sodium sulfate. Removal of the solvent and purification by column chromatography on a silica gel using benzene as an eluant gave the product as a yellow crystal $(0.77 \mathrm{~g}, 40 \%)$. M. p. 187-190 ${ }^{\circ} \mathrm{C}$. ${ }^{1} \mathrm{H}-\mathrm{NMR} \quad \delta \square \quad 0.89-0.95 \quad\left(\mathrm{~m}, \quad 12 \mathrm{H}, \quad \mathrm{OCH}_{2} \mathrm{CH}\left(\mathrm{CH}_{2} \mathrm{CH}_{3}\right)\left(\mathrm{CH}_{2}\right)_{3} \mathrm{CH}_{3}\right), \quad 1.30-1.55(\mathrm{~m}, \quad 16 \mathrm{H}$, $\mathrm{OCH}_{2} \mathrm{CH}\left(\mathrm{CH}_{2} \mathrm{CH}_{3}\right)\left(\mathrm{CH}_{2}\right)_{3} \mathrm{CH}_{3}$ ), 1.73 (septet, $2 \mathrm{H}, J=6.06 \mathrm{~Hz}, \mathrm{OCH}_{2} \mathrm{CH}\left(\mathrm{CH}_{2} \mathrm{CH}_{3}\right)\left(\mathrm{CH}_{2}\right)_{3} \mathrm{CH}_{3}$ ), $3.86\left(\mathrm{dd}, 4 \mathrm{H}, J=0.76,6.06 \mathrm{~Hz}, \mathrm{OCH}_{2} \mathrm{C}_{7} \mathrm{H}_{15}\right), 6.89$ (d, 4H, $\left.J=8.59 \mathrm{~Hz}, \mathrm{Ar}-\underline{\mathrm{H}}\right), 6.96(\mathrm{~d}, 2 \mathrm{H}, \quad J=$ $16.2 \mathrm{~Hz}, \mathrm{CH}=\mathrm{CH}), 7.07(\mathrm{~d}, 2 \mathrm{H}, J=16.2 \mathrm{~Hz}, \mathrm{CH}=\mathrm{CH}), 7.44(\mathrm{~d}, 4 \mathrm{H}, J=8.59 \mathrm{~Hz}, \mathrm{Ar}-H), 7.46(\mathrm{~s}, 4 \mathrm{H}$, Ar-H). ${ }^{13} \mathrm{C}-\mathrm{NMR}, \delta 11.50,14.47,23.44,24.27,29.49,30.93,39.79,71.01,115.16,126.47,126.90$, 128.03, 130.33, 137.06, 159.57. Anal. Calcd for $\mathrm{C}_{38} \mathrm{H}_{50} \mathrm{O}_{2}, \mathrm{C}, 84.71$; H, 9.35 (\%). Found, C, 84.53; $\mathrm{H}, 9.35(\%)$.

\section{Synthesis of 1,3-bis [(2'-ethylhexyloxy)styryl]benzene (4)}

This compound was prepared according to the procedure similar to the above olefination reaction using tert-BuOK (1.08 g, $9.42 \mathrm{mmol})$, the phosphonic acid ester (2.01 g, $5.64 \mathrm{mmol}$ ), and isophthalaldehyde $(0.48 \mathrm{~g}, 3.58 \mathrm{mmol})$ in THF. The product was obtained in $53 \%$ yield $(0.81 \mathrm{~g})$ as a white solid. M. p. 69-71 ${ }^{\circ} \mathrm{C} .{ }^{1} \mathrm{H}-\mathrm{NMR}, \delta$ 0.89-0.95 (m, $\left.12 \mathrm{H}, \mathrm{OCH}_{2} \mathrm{CH}\left(\mathrm{CH}_{2} \mathrm{CH}_{3}\right)\left(\mathrm{CH}_{2}\right)_{3} \mathrm{CH}_{3}\right)$, 1.30-1.53 (m, $\left.16 \mathrm{H}, \quad \mathrm{OCH}_{2} \mathrm{CH}\left(\mathrm{OCH}_{2} \mathrm{CH}_{3}\right)\left(\mathrm{CH}_{2}\right)_{3} \mathrm{CH}_{3}\right), 1.73$ (septet, $2 \mathrm{H}, \quad J=6.06 \mathrm{~Hz}$, 
$\left.\mathrm{OCH}_{2} \mathrm{CH}\left(\mathrm{CH}_{2} \mathrm{CH}_{3}\right)\left(\mathrm{CH}_{2}\right)_{3} \mathrm{CH}_{3}\right), 3.86\left(\mathrm{~d}, 4 \mathrm{H}, J=5.81 \mathrm{~Hz}, \mathrm{OCH}_{2} \mathrm{C}_{7} \mathrm{H}_{15}\right), 6.90(\mathrm{~d}, 4 \mathrm{H}, J=8.59 \mathrm{~Hz}$, $\operatorname{Ar}-H), 6.98$ (d, 2H, $J=16.4 \mathrm{~Hz}, \mathrm{CH}=\mathrm{CH}), 7.10$ (d, 2H, $J=16.2 \mathrm{~Hz}, \mathrm{CH}=\mathrm{CH}), 7.29-7.37$ (m, 3H, Ar-H), 7.45 (d, 4H, $J=8.84 \mathrm{~Hz}, \operatorname{Ar}-H), 7.59$ (s, 1H, Ar- $H$ ). ${ }^{13} \mathrm{C}$ NMR, $\delta 11.51,14.48,23.45,24.28$, 29.50, 30.94, 39.80, 71.01, 115.17, 124.61, 125.44, 126.72, 128.09, 128.93, 129.28, 130.25, 138.44, 159.63. Anal. Calcd for $\mathrm{C}_{38} \mathrm{H}_{50} \mathrm{O}_{2}, \mathrm{C}, 84.71 ; \mathrm{H}, 9.35$ (\%). Found. C, 84.60; H, 9.35 (\%).

\section{Synthesis of 1,2-bis [(2'-ethylhexyloxy)styryl]benzene (5)}

This compound was prepared according to the procedure similar to the olefination reaction described above using tert-BuOK (0.23 g, $2.08 \mathrm{mmol})$, the phosphonic acid ester $(0.74 \mathrm{~g}, 2.09$ mmol), and phthalaldehyde (1.04 g, $1.04 \mathrm{mmol})$ in DMF. The product was obtained in $17 \%$ yield $(0.096 \mathrm{~g})$ as a yellow liquid. ${ }^{1} \mathrm{H}$ NMR, $\delta$ 0.86-0.95 $\left(\mathrm{m}, 12 \mathrm{H}, \mathrm{OCH}_{2} \mathrm{CH}\left(\mathrm{CH}_{2} \mathrm{CH}_{3}\right)\left(\mathrm{CH}_{2}\right)_{3} \mathrm{CH}_{3}\right)$, 1.23-1.55 (m, 16H, $\left.\quad \mathrm{OCH}_{2} \mathrm{CH}\left(\mathrm{CH}_{2} \mathrm{CH}_{3}\right)\left(\mathrm{CH}_{2}\right)_{3} \mathrm{CH}_{3}\right), \quad 1.74 \quad$ (septet, $2 \mathrm{H}, \quad J=6.03 \mathrm{~Hz}$, $\left.\mathrm{OCH}_{2} \mathrm{CH}\left(\mathrm{CH}_{2} \mathrm{CH}_{3}\right)\left(\mathrm{CH}_{2}\right)_{3} \mathrm{CH}_{3}\right), 3.87$ (dd, 4H, $\left.J=1.01,6.03 \mathrm{~Hz}, \mathrm{OCH}_{2} \mathrm{C}_{7} \mathrm{H}_{15}\right), 6.90$ (d, 4H, $J=8.84$ $\mathrm{Hz}, \operatorname{Ar}-H), 6.94(\mathrm{~d}, 2 \mathrm{H}, J=16.2 \mathrm{~Hz}, \mathrm{CH}=\mathrm{CH}), 7.32$ (d, 2H, $J=16.2 \mathrm{~Hz}, \mathrm{CH}=\mathrm{CH}), 7.36(\mathrm{~s}, 2 \mathrm{H}$, Ar- $H), 7.45$ (d, 4H, J=8.84 Hz, Ar- $H), 7.54-7.57(\mathrm{~m}, 2 \mathrm{H}, \mathrm{Ar}-H)$.

\section{Synthesis of 1,3,5-tris(dimethylphosphonomethyl)benzene}

A mixture of trimethyl phosphite $(6.2 \mathrm{~mL}, 52.6 \mathrm{mmol})$ and 1,3,5-tri(bromomethyl)benzene (6.13.g, $17.2 \mathrm{mmol})$, prepared from trimesic acid (1,3,5-benzenetricarboxylic acid) by esterfication with ethanol followed by reduction with $\mathrm{LiALH}_{4}$ and then bromination with hydrobromic acid, was heated overnight at $120{ }^{\circ} \mathrm{C}$. Removal of the by-products such as ethyl bromide and dimethyl methylphosphonate under a reduced pressure and treatment with petroleum ether gave a white solid (6.43 g, 84 \%). ${ }^{1} \mathrm{H}-\mathrm{NMR}, \delta 3.14\left(\mathrm{~d}, 6 \mathrm{H}, J_{\mathrm{HP}}=22.2 \mathrm{~Hz}, \mathrm{CH}\right), 3.68\left(\mathrm{~d}, 18 \mathrm{H}, \mathrm{OCH}_{3}\right), 7.14(\mathrm{~s}, 3 \mathrm{H}$ Ar- $H) .{ }^{31} \mathrm{P}-\mathrm{NMR}$ (85\%, phosphoric acid as an external standard), $\delta 29.1$.

\section{Synthesis of 1,3,5-tris [(2'-ethylhexyloxy)styryl]benzene (6)}

This compound was prepared according to the procedure similar to the olefination reaction described above using tert-BuOK (0.68 g, $6.08 \mathrm{mmol})$, 1,3,5-tris(dimethylphosphonomethyl)benzene (1.01 g, $2.28 \mathrm{mmol})$, and 4-(2'-ethylhexyloxy)benzaldehyde (1.02 g, $4.34 \mathrm{mmol})$ in DMF. The product was obtained as a yellow liquid (0.30 g, $17 \%$ ). ${ }^{1} \mathrm{H}-\mathrm{NMR}, \delta \square 0.89-0.96(\mathrm{~m}, 18 \mathrm{H}$, $\left.\mathrm{OCH}_{2} \mathrm{CH}\left(\mathrm{CH}_{2} \mathrm{CH}_{3}\right)\left(\mathrm{CH}_{2}\right)_{3} \mathrm{CH}_{3}\right)$, 1.23-1.56 (m, $\left.24 \mathrm{H}, \mathrm{OCH}_{2} \mathrm{CH}\left(\mathrm{CH}_{2} \mathrm{CH}_{3}\right)\left(\mathrm{CH}_{2}\right)_{3} \mathrm{CH}_{3}\right)$, 1.74 (septet, $\left.3 \mathrm{H}, J=6.06 \mathrm{~Hz}, \mathrm{OCH}_{2} \mathrm{CH}\left(\mathrm{CH}_{2} \mathrm{CH}_{3}\right)\left(\mathrm{CH}_{2}\right)_{3} \mathrm{CH}_{3}\right), 3.87$ (dd, $\left.6 \mathrm{H}, J=1.01,6.06 \mathrm{~Hz}, \mathrm{OCH}_{2} \mathrm{C}_{7} \mathrm{H}_{15}\right)$, 
$6.91(\mathrm{~d}, 6 \mathrm{H}, J=8.59 \mathrm{~Hz}, \mathrm{Ar}-\mathrm{H}), 7.00(\mathrm{~d}, 3 \mathrm{H}, J=16.2 \mathrm{~Hz}, \mathrm{CH}=\mathrm{CH}), 7.14(\mathrm{~d}, 3 \mathrm{H}, J=16.2 \mathrm{~Hz}$, $\mathrm{C} H=\mathrm{CH}), 7.47(\mathrm{~d}, 6 \mathrm{H}, J=8.59 \mathrm{~Hz}, \mathrm{Ar}-H), 7.48(\mathrm{~s}, 3 \mathrm{H}, \mathrm{Ar}-H) .{ }^{13} \mathrm{C} \mathrm{NMR}, \delta 11.54,14.48,23.46$, $24.28,29.50,30.94,39.80,71.02,115.18,123.48,126.66,128.12,129.10,130.25,138.71,159.66$.

\section{Measurement of $\Phi_{C L}$}

For a typical run, a solution containing the oxalates in THF $\left(0.5 \mathrm{~mL}, 7.5 \times 10^{-4} \mathrm{M}\right)$ was added to a solution $(1,5 \mathrm{~mL})$ containing sodium carbonate $\left(2.5 \times 10^{-4} \mathrm{M}\right)$, fluorophores $\left(1.0 \times 10^{-4} \mathrm{M}\right)$, hydrogen peroxide $\left(4.0 \times 10^{-2} \mathrm{M}\right)$, and the surfactants of various concentrations in distilled water in a quartz cell placed in front of the photomultiplier at $25^{\circ} \mathrm{C}$. The photons generated over a $1000 \mathrm{sec}$. period were counted. The average of the values obtained by a few measurements was used for the calculation of $\Phi_{\mathrm{CL}}$.

\section{Results and Discussion}

\section{Absorption and fluorescence spectra of the oligophenylenevinylene fluorophores}

The structures of the oligophenylenevinylenes used in this study are shown in Fig. 1. 2-Ethylhexyloxy (OEH) groups were introduced as the residues enhancing both the electron-donating properties and the solubility toward organic solvents $(21,22)$. Their selected physical properties are shown in Table 1, in which some pronounced characteristics should be noted. Comparing the three oligophenylenevinylenes (1-3) with linearly extended conjugate systems, the extension of the conjugated system leads to a red-shift in the maximum absorption and fluorescence wavelengths and an increase in the fluorescence quantum yields ( $\Phi F)$. In addition, it is interesting to note that the oxidation potential (Eox) deeply involved with the CL efficiency tends to become higher with extension of the $\pi$-conjugation. The highest Stokes shift was found in 5, which suggests the specific character of this compound with the ortho-occupation of two styryl groups, namely, steric hindrance would provide significantly different structures between the ground and excited states. Fluorophore 6, with a dendritic structure, is characterized by shorter absorption and emission wavelengths compared with the others (23).

\section{PO-CL using the oligophenylenevinylenes as fluorophores}

The CL reactions of TCPO in the presence of fluorophores 1-6 were carried out under basic conditions in aqueous THF, in which conditions including the solvents and reagents were 
chosen to achieve better results. For example, aqueous THF was used as the solvent for this system, instead of aqueous acetonitrile frequently used for PO-CL reactions because of the

solubility of the reactants, TCPO and fluorophores, and either potassium or sodium carbonates was used for better CL efficiency. The results are summarized in Table 2. Because the CL and fluorescence spectra for the used fluorophores were in good agreement, light emission was produced in an indirect manner to form excited fluorophores by energy transfer from the high-energy intermediates to the fluorophores.

The singlet excitation yield ( $\Phi S)$ was calculated fromthe equation, $\Phi C L=\Phi r \AA \sim \Phi S \AA \sim \Phi F$, where $\Phi C L, \Phi r$ and $\Phi F$ are the total CL quantum yield, the yield of the chemical reaction, regarded as unity for the complete consumption of TCPO during the reactions, and the fluorescence quantum yield.Whereas the highest $\Phi C L$ was recorded using 2 as a fluorophore, $\Phi S$ was the greatest when 1 was used, which can be explained by a chemically initiated electron-exchange luminescence process (24-26) because of the close relation between the oxidation potentials of 1,2 and 3 and that of $\Phi S$. Despite the smaller $\Phi C L$ values of the three distyrylbenzenes 4, 5 and 6, compared with that of 2, the dendritic fluorophore 6 is also a good fluorophore for this CL system. This is probably due to the electron-donating ability of 6 by three alkoxy groups attached to the ends of the dendritic molecule.

Next, two aryl oxalates, 7 and 8, bearing ester groups with long alkyl chains, i.e. lauryl groups, at the meta- and para-positions, respectively, were prepared to explore the interaction between the oxalates and various kinds of surfactants (vide infra). The CL reaction was carried out in aqueous THF in the presence of 2 as a fluorophore under basic conditions. The results are shown in Table 3, in which the values of $\Phi C L$ reflect $\mathrm{T} 3$ the reactivity of the oxalates. The CL efficiency was related to the acidity of the phenoxy groups as the leaving groups (17). Thus, 7 was more reactive than 8 , and TCPO is $20-50$ times more reactive than the others.

\section{Effect of surfactants on the chemiluminescence efficiency}

To study their effect on CL efficiency, four categories of surfactants, anionic, cationic, amphoteric and non-ionic (Table 4), were employed in PO-CL enhanced by the distyrylbenzene fluorophore 2. Changes in the $\Phi C L$ of the PO-CL were measured using three oxalates, TCPO, 7 and 8 at each surfactant concentration, in which the concentrations of the surfactants were well above their CMCs. The results are shown in Fig. 2.

When the anionic surfactant SDS was added, a remarkable increase in ФCL was observed with increasing SDS concentration, whereas in the case of SDBS, a constant $\Phi C L$ value was maintained after its increase at a lower concentration of this surfactant. A similar tendency of SDS to increase the $\Phi C L$ in the PO-CL using other fluorophores, 4, 5 and 6, shows that the positive effect of SDS is 
common in the PO-CL system. The effect of anionic surfactants was furthermore established by enhancement of the CL efficiency when SHDS and STDS with longer alkyl chains than SDS were used, as shown in Fig. 3. By contrast, the opposite results F3 were observed when cationic surfactants were employed. A sharp decrease in $\Phi C L$ was detected with increasing concentrations of the cationic surfactants DTAB and DPC. Interestingly, the amphoteric surfactant, SB-12, having a cationic site within the chain and an anionic site at the end, behaved like both cationic and anionic surfactants, in which $\Phi C L$ decreased after an initial increase. The non-ionic surfactant, Briji 35, produced different results among the three oxalates, namely, $C \mathrm{CL}$ initially increased, but decreased with increasing surfactant concentration for the reaction of TCPO, whereas a sharp increase was found in the case of oxalates 7 and 8 with the long alkyl chains. In addition, the non-ionic surfactants, Brij 58 and Brij 78, with alkyl chains longer than Brij 35, were also used in the PO-CL reactions of oxalates 7 and 8 . Whereas Brij 58 was effective on $\Phi C L$ enhancement, similarly to Brij 35, Brij 78 with the longest alkyl chain was unexpectedly inferior to the others at the higher concentration.

These results indicate some important concerns about the effect of surfactant on PO-CL reactions. CL reactions proceed within a micellar system, but not within an inverted micellar system in mixed THF and water solvents (THF : $\mathrm{H} 2 \mathrm{O}=3: 1$ ), because of the different results for SDS and SDBS. A similar tendency should have been observed if the reactions occur in reaction fields surrounded by the anionic moieties of the inverted micelles formed by either SDS or SDBS. The difference in the behavior of SDS and SDBS is based on their structures, the latter of which is distinguished from SDS by the presence of a benzene ring at the end of the surfactant. In the present CL reaction, the hydrophobic chemical species are taken into the SDBS micelle core less effectively than in the SDS micelle core, because the dodecyl chains in SDBS micelles are more tightly packed and less flexible than those in SDS micelle $(27,28)$. Since the fluorescence spectra of 2 did not change at the various SDS concentrations, an increase in $\Phi C L$ with the increase in $\Phi F$ of 2 in the hydrophobic spheres of the micelles is ruled out. The remarkable effect of the anionic surfactants, SDS, STDS and SHDS, can be explained by the increasing concentration of the interacting chemical species concerning the chemiexcitation process in the hydrophobic region of the SDS micelle, although the longer alkyl chain of these surfactants did not exactly give the higher CL efficiency. Here, it is important to note that the high-energy intermediates, the 4-aryloxy-4-hydroxy-1, 2-dioxetane-3-ones (17) or 1,2-dioxetane-3,4-dione, are formed by the reaction of oxalates with alkaline hydrogen peroxide and will concentrate and interact with the fluorophorewithin the hydrophobic area in the micelle. The higher the concentration of the anionic surfactants, the more the micelle number increases. It might be more important that these anionic surfactants prevent a rapid degradation of the oxalates by the hydrolysis under alkaline conditions 
$(8,29,30)$, because the negatively charged sulfate moiety of SDS would interrupt the contact between the active oxalates and the hydroxyl anions at the hydrophobic inside of the SDS micelle by the repulsive force of the negatively charged sulfate moieties at the periphery of themicelle. By contrast, the cationic surfactants take the hydroxyl ions in the micelle core to promote a significant degradation of the oxalates. The negative effect of DTAB is not completely due to the fluorescence quenching effect of a bromide ion, as sometimes mentioned, but chiefly due to its cationic character, because DPC as well as SB-12 showed a negative effect. However, the effect of SDS cannot explain the difference in CL efficiency among the oxalates, TCPO, 7 and 8, as shown in Fig. 2, namely, TCPO and 8 showed CL efficiencies five times larger than 7, and therefore the reactivity of the oxalates did not correlate completely with their CL efficiencies in this system. Finally, despite some points not being well elucidated, the surfactant effect is highly dependent on the surfactant properties, that is, various effects would occur based on the choice of the luminophore, fluorophore and surfactant.

\section{Conclusions}

Some fluorescent oligophenylenevinylenes were used in PO-CL as fluorophores, and the distyrylbenzenes were found to be the most effective enhancer of all in this study. The effect of surfactants on CL efficiency was also investigated in a PO-CL system enhanced by the distyrylbenzene fluorophore. The anionic surfactant showed a positive effect, increasing efficiency of the three oxalate CL reactions, whereas cationic surfactants led to reduced CL efficiency as their concentrations increased. The affinity of the alkyl chains introduced into the oxalates for the non-ionic surfactants contributed to the increase in CL intensities. Protection of the active oxalates from rapid alkaline hydrolysis by the surfactants is important, as is the concentration of the reactants at the hydrophobic micelle core.

\section{References}

1. Catherall CLR, Palmer TF, Cundall RB. Determination of absolute chemiluminescence quantum yields for reactions of bis-(pentachlorophenyl) oxalate, hydrogen peroxide and fluorescent compounds. J Biolumin Chemilumin 1989;3:147-54.

2. Chandross EA. A new chemiluminescent system. Tetrahedr Lett 1963;761-5.

3. Tsunoda M, Imai K. Analytical applications of peroxyoxalate chemiluminescence. Anal Chim Acta 2005;541:12-23. 
4. Carcia-Campana AM, Lara FJ. Trends in the analytical applications of chemiluminescence in the liquid phase. Anal Bioanal Chem 2007;387:165-9.

5. Barnett NW, Bos RB, Lewis SW. Rational design and preliminary analytical evaluation of two novel oxamide reagents for aqueous peroxyoxalate chemiluminescence. Russell RA, Analyst 1998;123:1239-45.

6. Abdel-Latif MS, Guilbault GG. Fiber-optic sensor for the Determination of glucose using micellar enhanced chemiluminescence of the peroxyoxalate reaction. Anal Chem 1988;60:2671-4.

7. Thompson RB, McBee SES. Peroxyoxalate chemiluminescence in microemulsions. Langmuir 1988;4:106-10.

8. Steijger OM, v. Mastbergen HM, Holthuis JJM. Chemiluminescence of bis(2,4,6-trichlorophenyl) oxalate in aqueous micellar systems. Anal Chim Acta 1989;217:229-37.

9. Dan N, Lau ML, Grayeski ML. Micellar-enhanced aqueous peroxyoxalate chemiluminescence. Anal Chem 1991;63:1766-71.

10. Dan N, Grayeski ML. Effects of reversed micelles on peroxyoxalate chemiluminescence and analytical implications for determination of fluorophores. Langmuir 1994;10:447-53.

11. Liang SX, Li H, Lin JM. Reaction mechanism of surfactant-sensitizedd chemiluminescence of bis(2,4,6-trichlorophenyl) oxalate and hydrogen peroxide induced by gold nanoparticles. Lumin 2008;23:381-5.

12. Wada M, Abe K, Ikeda R, Harada S, Kuroda N, Nakashima K. Enhancement of peroxyoxalate chemiluminescence intensity by surfactants and its application to detect detergent. Talanta 2010;81:1133-6.

13. Yingqiong J, Lilin S, Dan H, Rui Y, Zhangsheng Q, Changqing Z. Peroxyoxalate chemiluminescence based on fluorescent conjugated polymer for the determination of Triton X-100. Chin J Chem 2011;29:575-80.

14. An YJ, Lee JH, Jeong SW. Partitioning of hydrogen peroxide between the gas and liquid phases in the presence of surfactant. Chemosphere 2007;68:1377-81.

15. Motoyoshiya J, Sakai N, Imai M, Yamaguchi Y, Koike R, Takaguchi Y, H. Aoyama. Peroxyoxalate chemiluminescence of $N, N^{\prime}$-bistosyl-1 $H, 4 H$-quinoxaline-2,3-dione and related compounds. Dependence on electronic nature of fluorophores. J Org Chem 2002;67:7314-8.

16. Koike R, Katayose Y, Ohta A, Motoyoshiya J, Nishii Y, Aoyama H. Poly(benzyl ether) dendrimers with strongly fluorescent distyrylbenzene cores as the fluorophores for peroxyoxalate chemiluminescence: insulating effect of dendritic structures on fluorescent sites. Tetrahedr 2005;61: 11020-6.

17. Maruyama T, Narita S, Motoyoshiya J. The Hammett correlation between distyrylbenzene 
substituents and chemiluminescence efficiency providing various sigma-values for peroxyoxalate chemiluminescence of several oxalates. J Photochem Photobiol A Chem 2013;252:222-31.

18. Wong MS, Li ZH. Multifunctional properties of monodisperse end-functionalized oligophenylenevinylenes. Pure Appl Chem 2004;76:1409-19.

19. Figueria-Duarte TM, Gegout A, Nierengarten JF. Molecular and supramolecular C60-oligophenylenevinulene conjugates. Chem Commun 2007;109-19.

20. Fengqiang Z, Motoyoshiya J, Nakamura J, Nishii Y, Aoyama H. Photochemical behavior of some $p$-styrylstilbenes and related compounds: spectral properties and photoisomerization in solution and in solid-state. Photochem Photobiol 2006; 82:1645-50.

21. Park LS, Han YS, Hwang JS, Kim SD. Synthesis of conjugated polymers containing anthracene moiety and their electro-optical properties. J Polymer Sci 2000;38:3173-80.

22. Pfeiffer S, Hoerhold HH. Investigation of poly(arylenevinylene)s. Part 41. Synthesis of soluble dialkoxy-substituted poly(phenylene alkenylidene)s by applying the Horner-reaction for condensation polymerization. Macromol Chem Phys 1999;200:1870-8.

23. Coya C, de Andres A, Zaldo C, Alvarez AL, Arredondo B, Gomez R, Segura JL, Seoane C, Full-solution-processed blue organic light emitting device based on a fluorescent 1,3,5-tristyrylbenzene stilbenoid small molecule. J App Phys 2009;105:044510-6.

24. McCapra F. Chemiluminescence of organic compounds. Progr Org Chem 1973;8:231-77.

25. McCapra F, Perring K, Hart RJ, Hann RA. Photochemistry without light. Reaction of active oxalate esters with anthracenophanes. Tetrahedr Lett 1981;22:5087-90.

26. Stevani CV, Silva SM, Waader WJ. Studies on the mechanism of the excited step in peroxyoxalate chemiluminescence. Eur J Org Chem 2000;4037-46.

27. Palazzesi F, Calvaresi M, Zerbetto F. A molecular dynamics investigation of structure and dynamics of SDS and SDBS micelles. Soft Matter 2011;7:9148-56.

28. Sharma VK, Mitra S, Johnson M, Mukhopadhyay R. Dynamics in anionic micelles: Effect of phenyl ring. J Phys Chem B 2013;117:6250-55.

29. Gamiz-Gracia L, Garcia-Campana AM, Ales-Barrero F, Cuadros-Rodriguez L. Determination of albumin in biological fluids by flow injection analysis using the peroxyoxalate chemiluminescent system in micellar medium. Anal Bioanal Chem 2003;377:281-6.

30. Soto-Chinchilla JJ, Gamiz-Gracia L, Garcia-Campana AM, Cuadros-Rodriguez L. A new strategy for thre chemiluminescent screening analysis of total $N$-methylcarbamate content in water. Anal Chim Acta 2005;541:113-8. 


\section{Captions}

Fig. 1 Structures of oligophenylenevinylene fluorophores used in the present study.

Fig. 2. Effect of the surfactants on the CL efficiencies using three oxalates, TCPO, 7, and $\mathbf{8}$. THF: $\mathrm{H}_{2} \mathrm{O}=3: 1$, [oxalates] $=1.88 \times 10^{-4} \mathrm{M},\left[\mathrm{Na}_{2} \mathrm{CO}_{3}\right]=1.88 \times 10^{-4} \mathrm{M},[2]=0.75 \times 10^{-4} \mathrm{M},\left[\mathrm{H}_{2} \mathrm{O}_{2}\right]=3.0 \times$ $10^{-2} \mathrm{M}$.

Fig. 3. Effect of anionic surfactants on the TCPO PO-CL. THF: $\mathrm{H}_{2} \mathrm{O}=3: 1$, $\left[\right.$ TCPO] $=1.88 \times 10^{-4} \mathrm{M}$, $\left[\mathrm{Na}_{2} \mathrm{CO}_{3}\right]=1.88 \times 10^{-4} \mathrm{M},[2]=0.75 \times 10^{-4} \mathrm{M},\left[\mathrm{H}_{2} \mathrm{O}_{2}\right]=3.0 \times 10^{-2} \mathrm{M}$.

Table 1. Physical properties of fluorophores 1-6.

\section{Foot notes:}

${ }^{a}$ Measured in THF at $1.0 \times 10^{-5} \mathrm{M}$.

${ }^{b}$ The data in the prentheses are the values measured in THF and water in the ratio of $3: 1$.

${ }^{c}$ Measured in $\mathrm{CH}_{2} \mathrm{Cl}_{2}$. [fluorophores] $=1.0 \times 10^{-4} \mathrm{M},\left[\mathrm{Bu}_{4} \mathrm{NClO}_{4}\right]=0.1 \mathrm{M}$.

${ }^{d}$ Not measured.

Table 2. Chemiluminescence quantum yields of peroxyoxalate chemiluminescence using TCPO in the presence of the fluorophores 1-6.

Foot notes:

${ }^{a} \mathrm{THF}: \mathrm{H}_{2} \mathrm{O}=3: 1,[\mathrm{TCPO}]=1.0 \times 10^{-5} \mathrm{M}$, [fluorophore $]=1.0 \times 10^{-5} \mathrm{M},\left[\mathrm{H}_{2} \mathrm{O}_{2}\right]=1.0 \times 10^{-2} \mathrm{M}$, $\left[\mathrm{K}_{2} \mathrm{CO}_{3}\right]=2.0 \times 10^{-4} \mathrm{M}$.

${ }^{b} \mathrm{THF}: \mathrm{H}_{2} \mathrm{O}=3: 1,[\mathrm{TCPO}]=2.5 \times 10^{-6} \mathrm{M}$, [fluorophore $]=2.5 \times 10^{-6} \mathrm{M},\left[\mathrm{H}_{2} \mathrm{O}_{2}\right]=2.5 \times 10^{-3} \mathrm{M}$, $\left[\mathrm{K}_{2} \mathrm{CO}_{3}\right]=5.0 \times 10^{-5} \mathrm{M}$.

${ }^{c}[\mathrm{TCPO}]=5.0 \times 10^{-5} \mathrm{M},[$ fluorophore $]=1.0 \times 10^{-4} \mathrm{M},\left[\mathrm{Na}_{2} \mathrm{CO}_{3}\right]=7.5 \times 10^{-4} \mathrm{M},\left[\mathrm{H}_{2} \mathrm{O}_{2}\right]=1.2 \mathrm{x}$ $10^{-1} \mathrm{M}$.

Table 3. Chemiluminescence quantum yield of oxalates, TCPO, 7 and $\mathbf{8}$ in the presence of $\mathbf{2}$ as a fluorophore.

\section{Foot notes:}

${ }^{a}$ A mixture of THF and water $(3 ; 1)$ was used as the solvents. [oxalate] $=5.0 \times 10^{-5} \mathrm{M},[2]=1.0 \mathrm{x}$ $10^{-4} \mathrm{M},\left[\mathrm{Na}_{2} \mathrm{CO}_{3}\right]=7.5 \times 10^{-4} \mathrm{M}$, $\left[\mathrm{H}_{2} \mathrm{O}_{2}\right]=1.2 \times 10^{-2} \mathrm{M}$.

Table 4. Structure of surfactants used in the present study.

Figures 1-3 

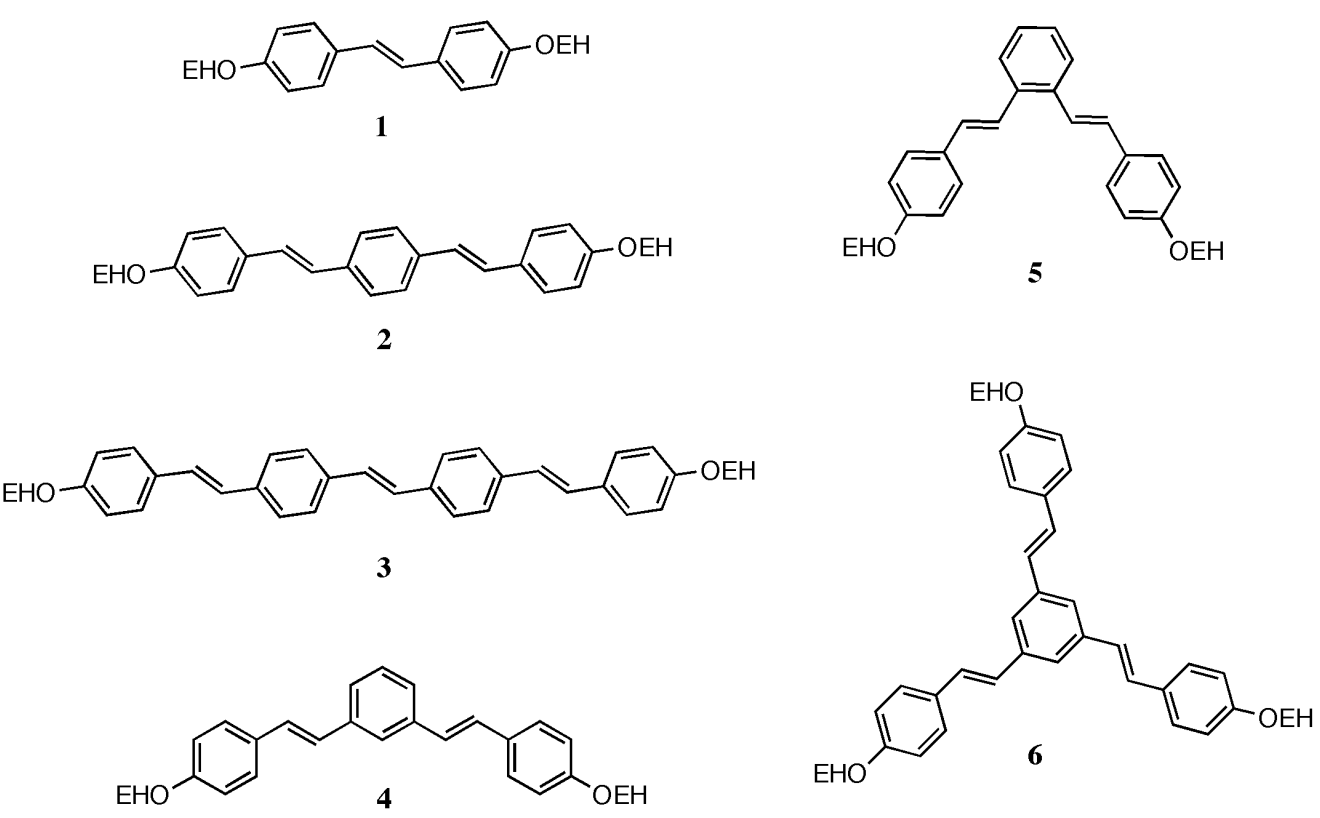

$E H=2$-ethylhexyl

Fig. 1. Structures of the fluorophores 1-6. 
TCPO-POCL enhanced by 2 in the presence of surfactants
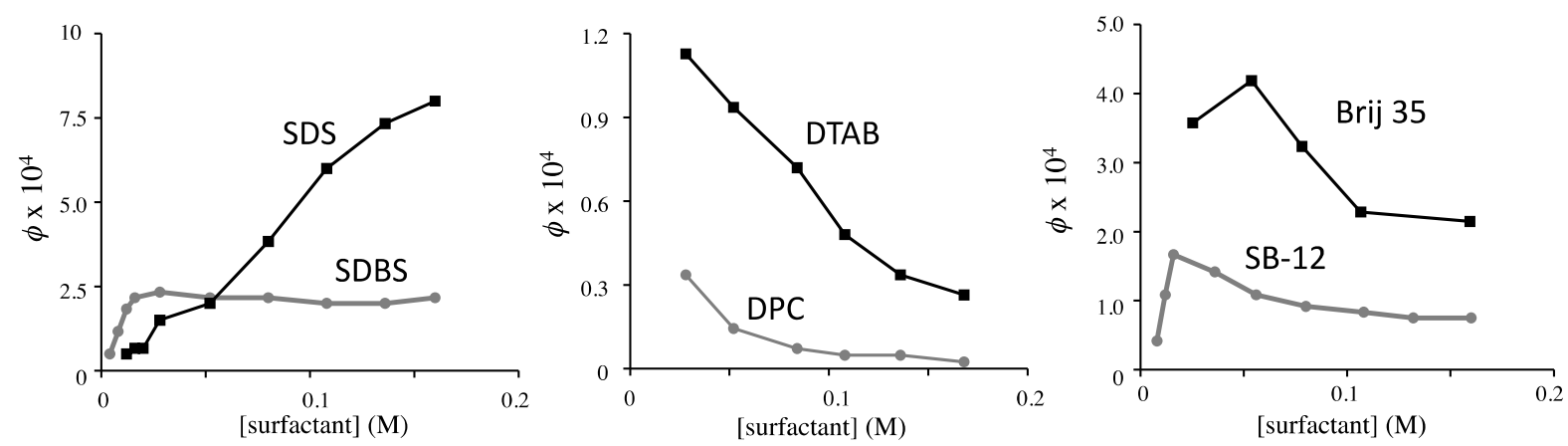

Oxalate 7-POCL enhanced by 2 in the presence of surfactants
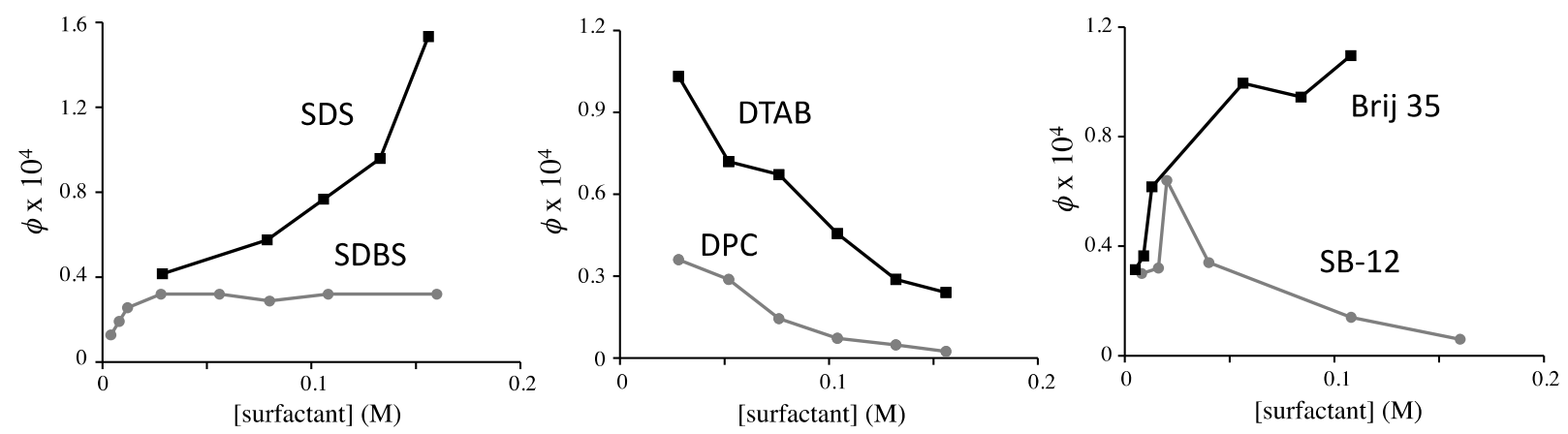

Oxalate 8-POCL enhanced by 2 in the presence of surfactants
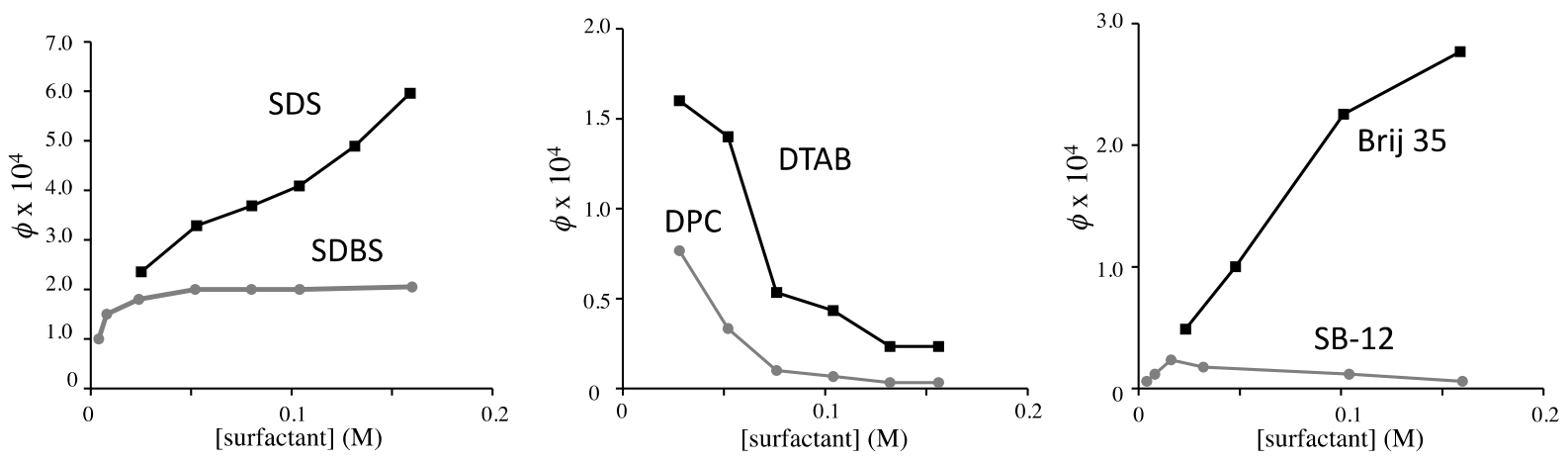

Fig. 2. Effect of the surfactants on the CL efficiencies using three oxalates, TCPO, 7, and $\mathbf{8}$.

THF: $\mathrm{H}_{2} \mathrm{O}=3: 1$, [oxalates] $=1.88 \times 10^{-4} \mathrm{M},\left[\mathrm{Na}_{2} \mathrm{CO}_{3}\right]=1.88 \times 10^{-4} \mathrm{M},[2]=0.75 \times 10^{-4} \mathrm{M}$, $\left[\mathrm{H}_{2} \mathrm{O}_{2}\right]=3.0 \times 10^{-2} \mathrm{M}$. 


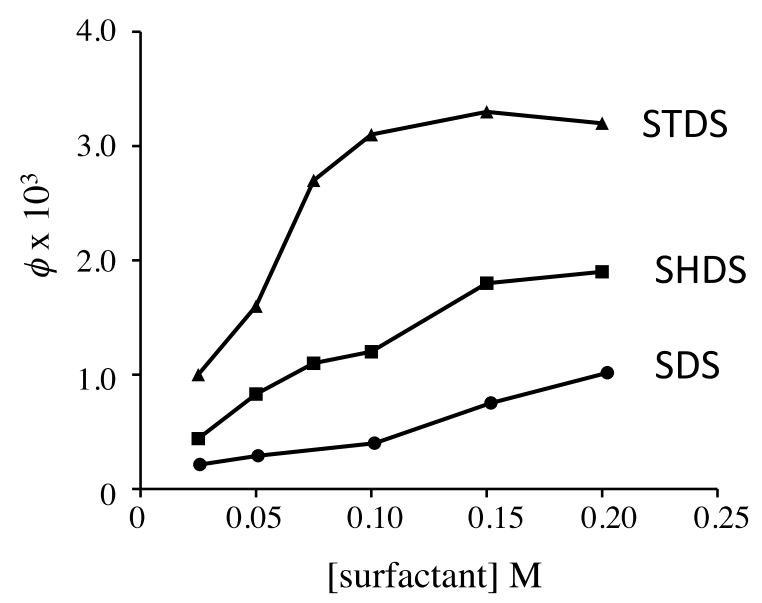

Fig. 3. Effect of anionic surfactants on the TCPO PO-CL.

THF: $\mathrm{H}_{2} \mathrm{O}=3: 1$, [TCPO] $=1.88 \times 10^{-4} \mathrm{M}$, $\left[\mathrm{Na}_{2} \mathrm{CO}_{3}\right]=1.88 \times 10^{-4} \mathrm{M},[2]=0.75 \times 10^{-4} \mathrm{M}$, $\left[\mathrm{H}_{2} \mathrm{O}_{2}\right]=3.0 \times 10^{-2} \mathrm{M}$.

Tables 1-4

Table 1. Physical properties of fluorophores 1-6.

\begin{tabular}{|c|c|c|c|c|}
\hline & $\frac{\text { Abs. } \max .}{\mathrm{nm}} a, b$ & $\frac{\mathrm{EM} . \max .}{\mathrm{nm}}^{a}$ & $\underset{\mathrm{F}}{a, b}$ & $\frac{E_{1 / 2 \mathrm{OX}}{ }^{c}}{\mathrm{~V} \text { vs, SCE }}$ \\
\hline 1 & 348 & 382 & 0.23 & 0.89 \\
\hline 2 & $368(368)$ & 432 & $0.71(0.67)$ & 1.03 \\
\hline 3 & 388 & 436 & 0.93 & 1.26 \\
\hline 4 & (325) & 431 & $(0.20)$ & --- $d$ \\
\hline 5 & (296) & 428 & $(0.15)$ & ${ }_{---} d$ \\
\hline 6 & $328(328)$ & 398 & $0.35(0.32)$ & --- \\
\hline
\end{tabular}

a Measured in THF at $1.0 \times 10^{-5} \mathrm{M}$. Estimated by comparison with 9,10-diphenylanthracene as a standard $\left(\sqrt{F}_{\mathrm{F}}=0.95\right) .{ }^{b}$ The data in the prentheses are the values measured in THF and water in the ratio of 3:1. ${ }^{c}$ Measured in $\mathrm{CH}_{2} \mathrm{Cl}_{2}$. [fluorophores] $=1.0 \times 10^{-4} \mathrm{M},\left[\mathrm{Bu}_{4} \mathrm{NClO}_{4}\right]=0.1 \mathrm{M} .{ }^{d}$ Not measured. 
Table 2. Chemiluminescence quantum yields of peroxyoxalate chemiluminescence using TCPO in the presence of the fluorophores 1-6.

\begin{tabular}{ccc}
\hline & $\frac{\mathrm{CL}^{\times 1} 10^{4}}{\text { einstein/ mol }}$ & $\frac{\mathrm{S} \times 10^{4}}{\text { einstein/ mol }}$ \\
\hline $\mathbf{1}$ & $2.2^{a}$ & 9.6 \\
$\mathbf{2}$ & $3.9^{b}$ & 4.2 \\
$\mathbf{3}$ & $1.2^{c}$ & 1.3 \\
$\mathbf{4}$ & $0.22^{c}$ & 2.7 \\
$\mathbf{5}$ & $0.13^{c}$ & 2.1 \\
$\mathbf{6}$ & $0.67^{c}$ & 5.0 \\
\hline
\end{tabular}

${ }^{a} \mathrm{THF}: \mathrm{H}_{2} \mathrm{O}=3: 1$, [TCPO] $=1.0 \times 10^{-5} \mathrm{M}$, [fluorophore $]=1.0 \times 10^{-5} \mathrm{M}$, $\left[\mathrm{H}_{2} \mathrm{O}_{2}\right]=1.0 \times 10^{-2} \mathrm{M},\left[\mathrm{K}_{2} \mathrm{CO}_{3}\right]=2.0 \times 10^{-4} \mathrm{M}$.

$b$ THF : $\mathrm{H}_{2} \mathrm{O}=3: 1$, [TCPO] $=2.5 \times 10^{-6} \mathrm{M}$, [fluorophore $]=2.5 \times 10^{-6} \mathrm{M}$, $\left[\mathrm{H}_{2} \mathrm{O}_{2}\right]=2.5 \times 10^{-3} \mathrm{M},\left[\mathrm{K}_{2} \mathrm{CO}_{3}\right]=5.0 \times 10^{-5} \mathrm{M}$.

${ }^{c}[\mathrm{TCPO}]=5.0 \times 10^{-5} \mathrm{M}$, [fluorophore $]=1.0 \times 10^{-4} \mathrm{M}$, $\left[\mathrm{Na}_{2} \mathrm{CO}_{3}\right]=7.5 \times 10^{-4} \mathrm{M},\left[\mathrm{H}_{2} \mathrm{O}_{2}\right]=1.2 \times 10^{-1} \mathrm{M}$.

Table 3. Chemiluminescence quantum yield of oxalates, TCPO, 7 and 8 in the presence of 2 as a fluorophore.

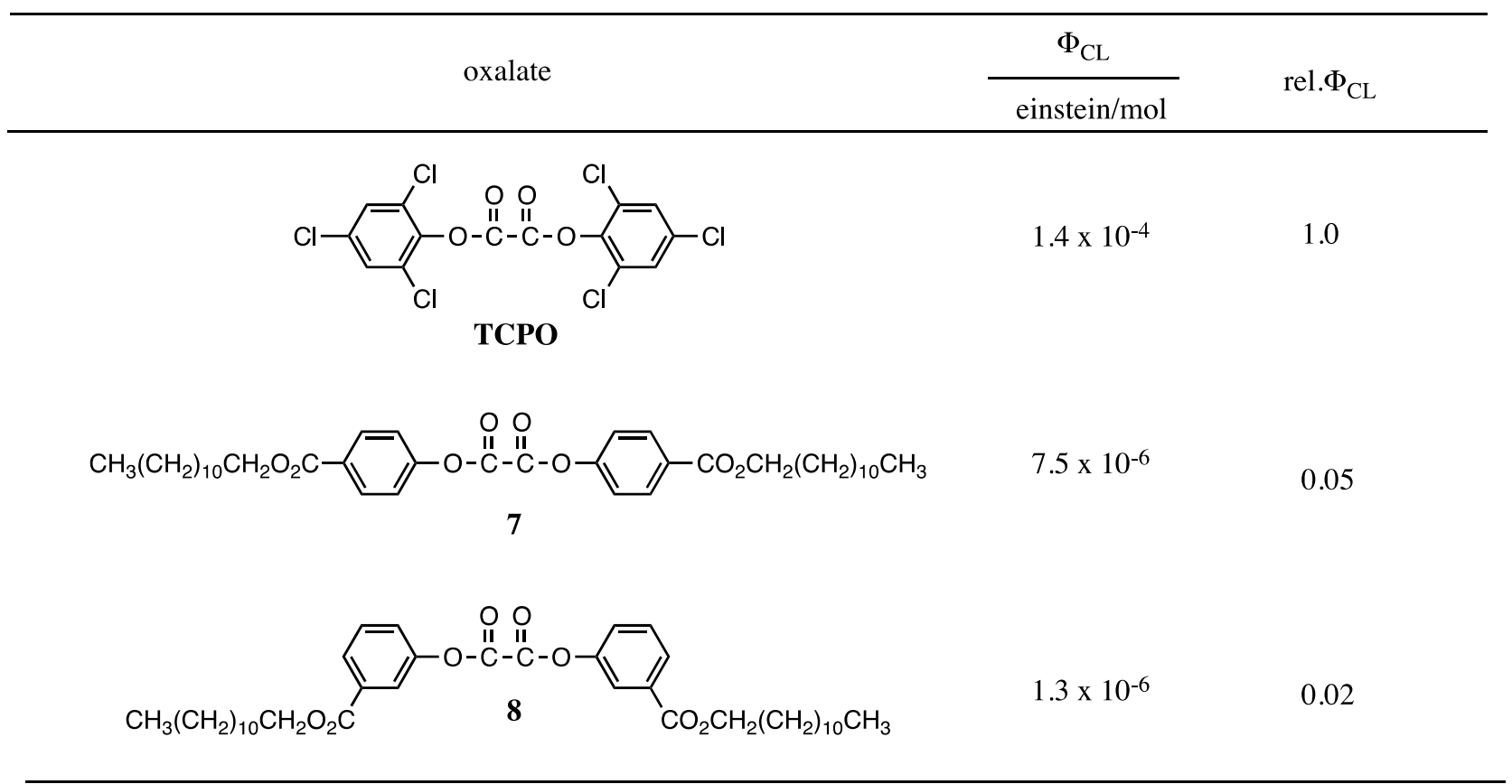

${ }^{a}$ A mixture of THF and water $(3 ; 1)$ was used as the solvents. [oxalate] $=5.0 \times 10^{-5} \mathrm{M},[2]=1.0 \mathrm{x}$ $10^{-4} \mathrm{M},\left[\mathrm{Na}_{2} \mathrm{CO}_{3}\right]=7.5 \times 10^{-4} \mathrm{M},\left[\mathrm{H}_{2} \mathrm{O}_{2}\right]=1.2 \times 10^{-2} \mathrm{M}$. 
Table 4. Structure of surfactants used in the present study.

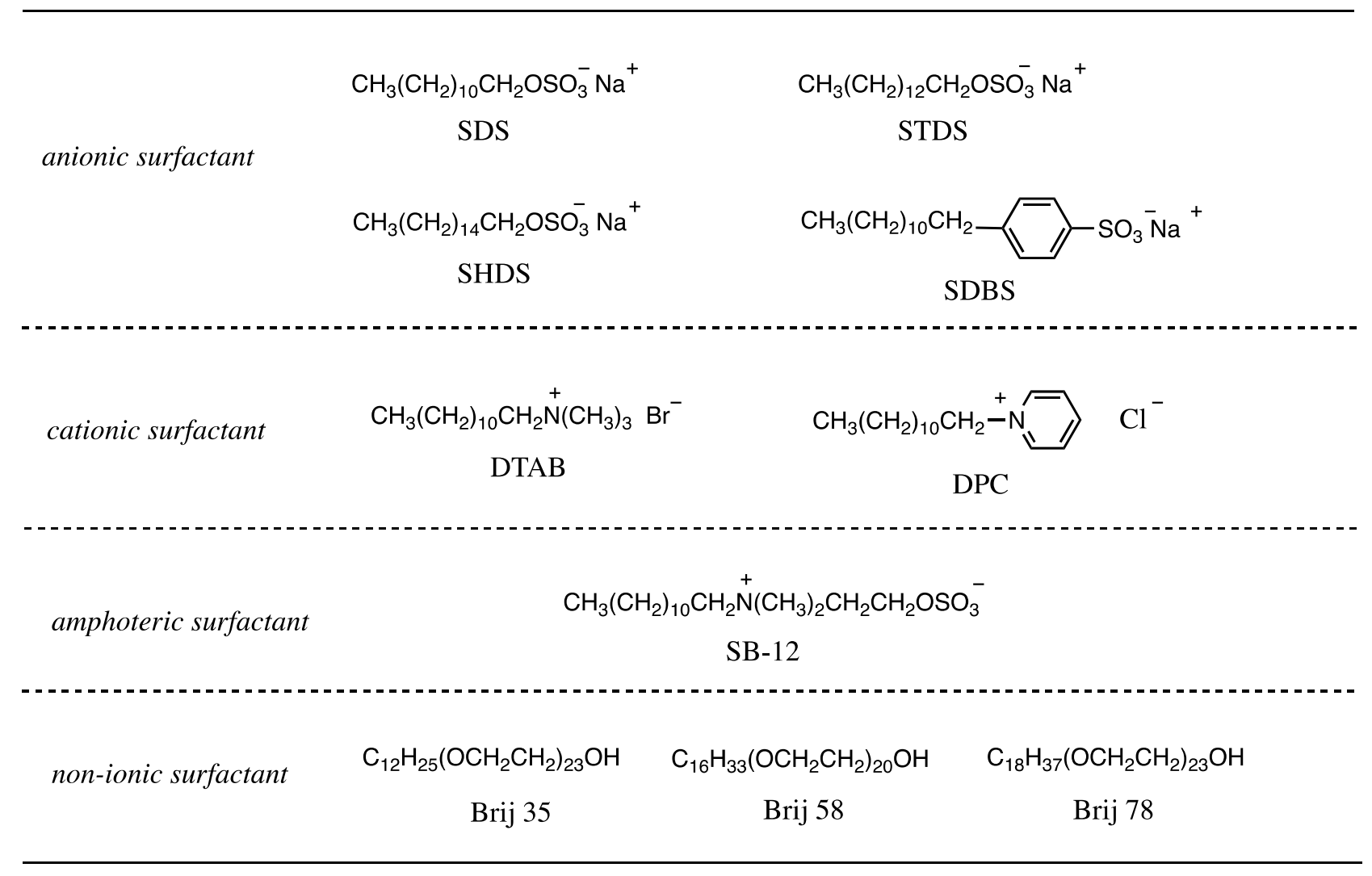

